\title{
Algumas considerações sobre os dados e métodos empregados para definir a fronteira entre a prática da arte e do design.
}

\author{
Some considerations about the data and methods used to define the border between \\ the practice of art and the practice of design.
}

Karla G. Schwartz - doutoranda em Arte e Design da Pontifícia Universidade Católica do Rio de Janeiro (PUC-Rio). Email: kgsrio@gmail.com;

Dr. Alberto Cipiniuk - Orientador e Professor do programa de pós-graduação em Arte e Design da Pontifícia Universidade Católica do Rio de Janeiro (PUC-Rio). Email: cipiniuk@puc-rio.br

RESUMO Este artigo descreve etapas percorridas em pesquisa de doutorado em Arte e Design, iniciada em março de 2017. Percebida como pouco nítida a fronteira entre a prática da Arte e do Design, objetiva-se analisar comparativamente ambas e apurar diferenças e semelhanças. Por prática entenda-se prática social ou trabalho. $O$ estudo comparativo das mencionadas atividades pode auxiliar na reflexão da questão do Design ser entendido como um Campo independente, dotado de estatuto ontológico. Ou, contrariamente, entender-se que sua atividade não difere substancialmente daquela dos artesãos/artistas. Neste caso, o Design teria suas origens no Campo da Arte, sem se diferenciar suficientemente do último para ser um Campo distinto. Tem-se como hipótese a ideia de que a prática dos aspectos mais significativos do Design, executada pelo designer, bebe diretamente da fonte daquilo que desde o início da Idade Moderna se chama de Arte. Ambas as atividades, desde seu nascimento, partilham um passado comum.

PALAVRAS-CHAVE Prática do Design; prática da Arte; análise comparativa.

ABSTRACT This article describes the steps of a doctoral research in Art and Design, initiated in March 2017. The frontier between the practices of Art and Design is perceived as unclear. The objective of the research is to analyze both practices, comparing differences and similarities. Practice is defined as a social practice or work. The comparative study can help in addressing the question of Design as an independent field, endowed with ontological status. Alternatively, Design can be understood as an activity not differing substantially from those of artisans / artists in the Art field. In this case, Design has its origins in the art field without sufficient differences as a distinct field. The hypothesis is that the practice of the most significant aspects of Design, executed by the designer, has the same source of what has been called Art since the Modern Age. Both activities share a common past since inception.

KEYWORDS Design practice; Art practice; comparative analyses. 


\section{Algumas considerações sobre os dados e métodos empregados para definir a fronteira entre a prática da arte e do design.}

O presente artigo descreve uma parte importante e propedêutica da pesquisa de doutorado que vem sendo realizada desde março de 2017, em sede do programa de pós-graduação em Artes e Design da Pontifícia Universidade Católica do Rio de Janeiro (PUC-Rio), sob a orientação do Professor Doutor Alberto Cipiniuk. Dá-se continuidade à linha de pesquisa desenvolvida pelo Grupo de Estudos em Design, Arte e Representação Social (GRUDAR) que compreende o Design e a Arte equivalentes a todas as outras práticas sociais que são percebidas como manifestações criadoras livres. Contudo, logo em primeira instância, manifesta-se contrariamente à noção de que as denominadas práticas criativas são expressões livres das ações humanas e individuais. Defende-se, de maneira oposta, que as mesmas espelham crenças e costumes de suas sociedades e, portanto, caracterizam-se necessariamente como coletivas. A criatividade não é livre, pois se realiza em estruturas sociais e nunca fora delas. Daí verifica-se que a afirmação que se refuta guarda um viés idealista, pois entende a liberdade como algo em si mesmo, como um dado universal fixo e válido para sempre, em qualquer contexto histórico, contudo, os próprios contextos históricos nos esclarecem que a liberdade não se postula no vazio social, desse modo o que é livre hoje, pode não ser amanhã.

Para efeito desse trabalho, definimos a criação livre como uma abstração filosófica, que possui a restrita validade de uma hipótese teórica. Do mesmo modo, a vista desarmada, aqueles que se dedicam aos trabalhos que se denominam criativos nunca o realizam de modo solitário. É preciso considerar que quem exerce uma prática denominada criativa é visto como alguém que possui uma natureza especial e diferenciada de todos os outros homens e mulheres. Julga-se que essa noção é um equívoco teórico e em razão de seus agentes se encontrarem sempre inseridos em um dado contexto social, sujeitando-se, portanto, às múltiplas e constantes influências de seu meio, seja em nível consciente como inconsciente, o exercício dessa prática é coletivo. Defende-se que o ambiente no qual o artesão/artista ou designer está inserto influencia ou mesmo determina, mas não inteiramente, a produção criativa humana. Linda Nochlin já alertava para a necessidade de se repensar a História da Arte a fim de se corrigir incorreções, inadequações, visões tendenciosas tais como a noção da genialidade inata do artista.

\footnotetext{
Quando forem feitas as perguntas certas sobre as condições da atividade artística, sendo a produção da grande arte um subtópico, não haverá dúvida de que a discussão se dará acerca das concomitantes situacionais de inteligência e talento do que apenas ao gênio artístico. Piaget e outros destacaram em suas epistemologias genéticas que, no que diz respeito ao desenvolvimento da razão e da imaginação nas crianças, a inteligência ou, por implicação, o que escolhemos chamar de gênio, é uma atividade dinâmica, mais do que uma essência estática, de um sujeito em dada situação. Como nos mostram outras pesquisas no campo do desenvolvimento infantil, estas habilidades ou inteligência são construídas minuto a minuto, passo a passo, desde a infância, e os padrões de adaptação-
} 
acomodação podem ser estabelecidos de forma tão precoce em um indivíduo, que as faça parecer inatos ao observador menos atento. Tais investigações implicam, mesmo excluindo as razões meta-históricas, que acadêmicos terão que abandonar a noção, conscientemente ou não, de gênio individual como inata e imprescindível para a criação de arte (NOCHLIN, 1971, tradução de Juliana Vacaro, 2016: 22).

O grupo de estudos antes mencionado também tem como pedra angular de pesquisa responder à pergunta o que é isso que se chama de Design, sendo o mesmo, então, entendido como mais uma prática social. Entretanto, longe de ser unânime, tal visão compete com correntes de pensamento diversas. Para uma delas, o Design se encarregaria unicamente de agregar um elemento meramente decorativo aos objetos industriais, conferindo-se-lhe assim o caráter de prática artística aplicada à indústria. Outra corrente, que identificamos como sendo idealista, concebe o Design como um método especifico que almeja solucionar problemas. Leia-se: $A$ maior parte da literatura dos últimos cinquenta anos nos faria supor que o principal objetivo do design é tornar os objetos belos. Alguns estudos sugerem que se trata de um método especial de resolver problemas [...] (Forty, 2007: 11). Há ainda quem compreenda o Design da maneira antiga, isto é, como os filósofos idealistas compreendiam as ações humanas, enfim, como uma ciência essencialista e de valores absolutos ${ }^{1}$, cujos contornos e escopos urgem ainda ser definidos. Segundo Stéphane Vial, de maneira geral, o Design ainda não produziu uma teoria ou um pensamento de si mesmo, tal como a Arte já o fez (VIAL, 2010:11). ${ }^{2}$ Ora, postula-se que o Campo do Design não precisa de um pensamento unicamente seu, mas que os pares do campo pensem suas práticas em relação a todas as outras, para que se possam identificar singularidades ou especificidades dessa área, pela importância que o tema da definição do que é isso que é o Design tem suscitado contemporaneamente. Diferentemente das vertentes teóricas apresentadas aqui sumariamente, as investigações até então realizadas e ainda em andamento buscam desenvolver uma visão comparativa de ambas as atividades acima mencionadas pelo filósofo francês, a fim de colaborar na identificação mais rigorosa de quais sejam as especificidades de cada uma dessas práticas, a justificar assim suas classificações como Campos distintos de conhecimento. A questão é objeto de exame intenso em países como França e Canadá, no intento de se elaborar um estatuto ontológico para o Design, partindo-se do pressuposto que suas fronteiras quanto a outros Campos são fluídas, nebulosas. Destacam-se como pesquisadores dessa linha de pensamento Stéphane Vial,

\footnotetext{
${ }^{1}$ Um valor absoluto é algo pleno e acabado e que não se pode contestar. No âmbito acadêmico, não existem ideias ou coisas incontestáveis. A corrente idealista apresenta suas afirmações como "absolutas”, por exemplo: o artista já nasce artista. Essa é uma afirmação absoluta, pois considera que o que define o artista é uma circunstância interna que por algum motivo obscuro se inicia quando alguém nasce. Ela desconsidera que possam existir outras circunstâncias de natureza externa, tais como o tipo de educação ou o estímulo que essa pessoa obteve de suas famílias, circunstâncias essas que podem definir o mesmo fenômeno. Como os argumentos defendidos pelos idealistas em sua maior parte são absolutos pode-se dizer, portanto, que são dogmáticos.

${ }^{2}$ Le design ne cesse de penser, mais il est incapable de se penser. Il n'a encore jamais produit une théorie de lui-même, comme l'art a pu le faire. Seules quelques formules édifiantes dues à une poignée de designers célèbres ont vu le jour.
} 
acima mencionado, Professor da Faculdade de Nîmes e membro do Institut ACTE (UMR 8218, CNRS/Université Paris 1); e Alain Findeli e Rabah Bousbaci, ambos Professores da École de design industriel da Université de Montréal. No Brasil, o estudo tem sido encabeçado pelo Professor Alberto Cipiniuk, doutor em filosofia e letras pela Université Libre de Bruxelles, contando com a colaboração de seus orientandos nos programas de mestrado e doutorado em Artes e Design da Pontifícia Universidade Católica do Rio de Janeiro (PUC-Rio). A relevância do tema também foi percebida pelo Historiador Rafael Cardoso Denis (2012: sem paginação/on line):

\title{
VIVA O APRENDIZADO!
}

Diante de tantas mudanças no design e no mundo, compete repensar o escopo de atuação do campo para melhor definir seu papel atual. Em decorrência dos embates históricos que contribuíram para a consolidação da profissão, os designers têm o mau hábito de pensar sobre o que fazem principalmente em contraposição àquilo que não são ou àquilo que pertenceria a outros campos. Como toda identidade nova, os profissionais de design foram obrigados, historicamente, a se definir por meio de oposições e aproximações.

Os bens materiais resultantes do trabalho realizado pelo artista ou então por aqueles que se atém à prática do design são criações humanas, de homens e mulheres reais e que vivem em sociedade. Nossa principal indagação se resume em definir quando esses trabalhos são semelhantes ou quando diferem e, quando diferem, o fazem em razão de quê? Humildemente acredita-se que a análise dessa questão possa pensar o que seja o exercício do Design e logo, servir para um fim maior, para elaborar um estatuto ontológico para a prática. Tal conhecimento poderia permitir que dúvidas quanto à função social do Design na sociedade contemporânea e seus limites éticos e sustentáveis de atuação fossem dirimidas. Contrariamente, poderia levar à conclusão de que ambas as atividades são semelhantes, sendo o design, de fato, um ramo daquilo que historicamente tem-se chamado de Arte, cuja especificidade seria sua aplicabilidade aos objetos industriais e serviços e a maior usabilidade gerada aos mesmos, possibilitando o consumo em larga escala pela população mundial.

\begin{abstract}
Se tomarmos "arte" no sentido restrito, de artes plásticas, é verdade que design não é arte. Somente os projetos mais sofisticados de design teriam condição de pleitear tal designação. Se tomarmos "Arte" em sentido amplo, com A maiúscula, design é uma de suas manifestações, sem dúvida. Arte é um meio de acesso ao desconhecido, em pé de igualdade com a ciência, a filosofia, a religião - enfim, os poucos caminhos que o ser humano encontrou para relacionar seu interior com o universo que o cerca - $e$, nesse sentido, design é uma categoria subordinada mais à arte que aos outros três citados. Afinal, design é um campo dedicado à objetivação, à construção, à materialização de ideias. Compartilha com arte, arquitetura e engenharia o propósito de moldar formas, constituir espaços e definir relações por intermédio de marcadores visuais e táteis. (DENIS, 2011, on line)
\end{abstract}

Para que se possa elaborar um esboço de entendimento sobre as diferenças e semelhanças das duas práticas em questão, decidiu-se estudar a realização do trabalho artesanal, hoje chamado de criativo, através de um recorte histórico mais longo, desde a passagem da Idade Média para a Idade Moderna, haja vista o fato de que hoje a maior parte dos objetos é manufaturada por processos industriais uniformizados, o que impede, no caso do design, que ele possa ser 
compreendido como livre e criativo. Criativo, portanto, no presente estudo é algo visto como inovador, rebelde, e que não se sujeita as peias da indústria. Assim, propõe-se examinar panoramicamente, a partir do período medieval na Europa Ocidental, como eram as práticas sociais que hoje chamamos de criativas, suas regulamentações, métodos de ensino, instâncias de legitimação etc. O recorte quanto à época e território selecionados justifica-se pelos seguintes motivos: primeiramente, trata-se do momento histórico imediatamente anterior à distinção futura feita entre artesão e artista que surge e ganha a força de dogma durante a Idade Moderna, revolucionando a concepção humana do que seja a produção artística em comparação à produção artesanal, com reflexos até os dias atuais.

A divisão clara das formas de arte em artes plásticas e artes decorativas, ou mais simplemente, as artes e os ofícios, surgiu no Renascimento e se reflete em mudanças na educação artística, de oficinas artesanais para academias e nas teorias de arte produzidas por aquelas academias. Em meados do século XIX, o divórcio completo da "arte superior" $e$ do artesanato era motivo de grande preocupação para o marido de Jane Morris, William Morris, que olhou de volta para a Idade Média quando essa divisão prejudicial não era tão absoluta.(PARKER \& POLLOCK, 2013: 50, tradução nossa) ${ }^{3}$

Em guardando a prática do Design semelhanças profundas com a prática da Arte, há que se compreender como, porque e a partir de quando os objetos da cultura denominados criativos passaram a ser imbuídos de valor artístico, considerado, muitas vezes, desde então, superior ao valor de uso dos mesmos. Bernd Löbach, importante teórico alemão do Design, apóia-se no argumento das funções - prática, estética e simbólica - dos produtos industriais como meio de classificação dos mesmos e escreve sobre como a ornamentação de bens desde a Idade Média serviu para conferir prestígio e afirmar o status social de certas classes sociais. Defende que a configuração dos bens industriais, mas pode-se aqui compreender a dos bens de uso de maneira geral, em uma dada sociedade, somente pode ser entendida por meio da observação e compreensão das formas de vida dos homens na época e local considerados. O desenvolvimento histórico da mencionada configuração seria a resposta à busca humana de satisfazer suas necessidades por meio da invenção e utilização de bens artificiais (2001: 67). O autor refere-se aos objetos de uso manufaturados no período compreendido entre a Idade Média e a era industrial para afirmar que $A$ configuração dos produtos e sua utilização era adaptada à posição social do usuário (Ibid.: 91). Enquanto bens usados pelas classes camponesas e burguesas eram indubitavelmente configurados para atender a necessidades prático-funcionais unicamente, aos bens utilizados por membros do clero e da nobreza eram acrescentados elementos estéticos como forma, cor, certos materiais. Assim se afirmava riqueza, poder político e nível cultural de uma classe

\footnotetext{
${ }^{3}$ The clear division of art forms into fine arts and decorative arts, or more simple the arts and the crafts, emerged in the Renaissance and is reflected in changes of art education from craft-brased workshops to academies and in the theories of art produced by those academies. By the mid-nineteenth century the complete divorce of 'high art' and craft was a cause of considerable concern to Jane Morris's husband, William Moris, Who looked back to the Middle Ages when this damaging division was not so absolute.
} 
frente às demais. Ornados luxuosamente, tais bens eram acrescidos de uma dimensão estética e simbólica, orientada pelas artes em cada época. Muitos destes produtos de uso estavam tão dotados de adornos, que causava espanto ainda descobrir uma função prática neles (Ibid.: 91).

Percebe-se que além de funcionalidade, a prática do Design, tal como os profissionais de marketing gostam de dizer, "agrega valor" ao produto industrial, mas é preciso definir que coisa é essa que se "agrega", tal como é preciso definir isso que é "artístico" ou "criativo" na Arte. Portanto, muitas vezes designers e profissionais de marketing afirmam que sua competência profissional "agrega valor", mas valor de troca simbólica aos produtos industriais e aos serviços que fazem uso dele. Do mesmo modo, estendem essa noção para o Campo da Arte, afirmando que o trabalho do artista "agrega valor" às suas obras.

No momento em que se constitui um mercado da obra de arte, os escritores e artistas têm a possibilidade de afirmar- por via de um paradoxo aparente - ao mesmo tempo, em suas práticas e nas representações que possuem de sua prática, a irredutibilidade da obra de arte ao estado de simples mercadoria, e também, a singularidade da condição intelectual e artística. (BOURDIEU, 2007: 103)

Enfim, entende-se ser preciso definir com clareza que coisa é essa que se associa a um objeto industrial, assim como a uma obra considerada então de arte, e que o torna mais ou menos vendável ou consumível, haja vista que "agregar valor" a um objeto industrial não se dá naturalmente e sem uma intencionalidade qualquer.

A questão do valor de troca simbólica foi apresentada por Pierre Bourdieu (2007, passim) e vem sendo objeto de reflexão de diversos pensadores e sociólogos, mas ainda não chegou integralmente ao Campo do Design. Os produtos de nossa sociedade que são chamados de criativos têm a qualidade de refletir valores vigentes nas classes sociais das pessoas que os usam. Ter, possuir, fazer uso de tais bens ou serviços traz em si a ideia imbuída de pertencimento a uma determinada classe social. Essa noção é moderna e na Idade Média ela não existia. Na sociedade medieval o capital era a terra, assim o domínio de vastas extensões de terras obtidas violentamente pelo uso da força, outorgava a poucos privilegiados o título de nobre ou de senhor feudal. A propriedade da terra, além de seu valor de uso para a agricultura, este menos prestigiado, simbolizava a riqueza e a distinção e honradez de seu dono.

Antes de se avançar, é preciso esclarecer um ponto muitas vezes árido, mas extremamente importante para o tipo de análise que se realiza. A diferença entre valor de uso e valor simbólico de um objeto. Com a transição verificada entre os séculos XI e XIII da economia natural, baseada em permutas, para uma economia monetária, bens passaram a ser produzidos não mais unicamente para consumo próprio, mas com o intuito de servir de excedente para comercialização em troca de pagamento em metais, em moeda. Esse fenômeno social deu-se juntamente com a revitalização econômica da Europa que permitiu o arranque para a Idade Moderna. A ideia de riqueza que antes era associada ao domínio de terras se transferiu para a posse e acúmulo de moeda. A fim de se distinguir valor de uso de valor de troca simbólica, oferece-se o seguinte exemplo: um saco de 
grãos de trigo possui um valor concreto, o fato de que ele pode alimentar um número determinado de pessoas. Ele possui, portanto, um valor utilitário ou de uso social de base, mas pode ser trocado por outra coisa que possa ter outro valor, como um livro, embora ninguém possa comer um livro. $O$ sentido do valor de uso é muito simples e tangível, aqui se trata de um valor maior em relação à sobrevivência dos homens e mulheres. Mesmo que um livro possa ser muito importante para um grupo social, ele não é fundamental como um saco de grãos de trigo. Os antropólogos consideram que dependendo da cultura, esse ou aquele produto pode ser mais ou menos importante, com maior ou menor valor, dependendo de como o grupo social é estruturado.

O fato é que como os resultados da indústria humana são extremamente variados, era preciso de algo ou alguma coisa- uma moeda - que servisse para intermediar as trocas ou os negócios dessas coisas diferenciadas, daí a revitalização de uma economia monetária praticamente esquecida desde a queda do Império Romano, comprovado pelo surgimento das primeiras casas bancárias da Europa nas vésperas da Idade Moderna. O valor de troca aqui tratado, embora estivesse presente na história da humanidade, seja na área dos serviços, seja na compra e venda de bens materiais industriais, faz referência atualmente a uma economia de trocas simbólicas e que opera com outros valores que não os econômicos ou financeiros. Então hoje, por exemplo, vale tanto para um artista ser citado em um jornal de circulação nacional como ter a sua obra vendida por um preço elevado no mercado de compra e venda de arte. Evidentemente que essa distinção não existia no passado remoto. Na sociedade ocidental contemporânea, a propriedade de um determinado objeto consagrado pela sociedade, tal como uma obra de arte, ao qual se atribui historicamente um valor simbólico, ou por exemplo, o reconhecimento dos méritos de um indivíduo pelas massas, diga-se até que por motivos de menor importância, confere ao seu detentor um status social tanto ou mais significante do que sua efetiva reserva monetária.

Para que se pudesse trilhar criticamente fora da tradição filosófica idealista, além de Pierre Bourdieu, um autor empregado em nossa investigação, Zygmunt Bauman, nos explica essa questão do emprego do universo simbólico de modo bastante inovador,

Marcas, logos e grifes são os termos da linguagem do reconhecimento. O que se espera que seja e, como regra, deve ser reconhecido com a ajuda de grifes e logos é o que foi discutido nos últimos anos sob o nome de identidade. A operação acima descrita está por trás da preocupação com a identidade a que foi concedida tal centralidade em nossa sociedade de consumidores. Mostrar caráter e ter uma identidade reconhecida, assim como descobrir e obter os meios de assegurar a realização desses propósitos inter-relacionados, tornam-se preocupações centrais na busca de uma vida feliz. Embora continue sendo um tema importante e uma tarefa absorvente desde a passagem, ocorrida no início da Idade Moderna, da sociedade da atribuição para a da realização ou seja, de uma sociedade em que as pessoas nasciam em suas identidades para uma em que a construção da identidade é tarefa e responsabilidade delas, a identidade agora compartilha o destino de outros equipamentos da vida: espera-se e prefere-se que ela, na falta de uma direção determinada definitiva, e não mais destinada a deixar atrás de si traços sólidos e indestrutíveis, seja fácil de ser fundida e passível de ser remodelada em diferentes formatos. Antes um projeto para 


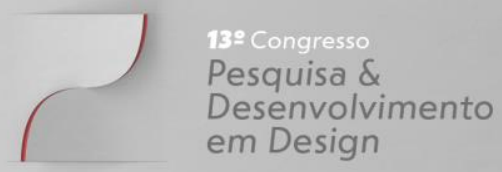

Artigo Completo

toda a vida, a identidade agora se transformou num atributo momentâneo. (BAUMAN, 2008: 24)

Retornando-se ao recorte territorial optado, explica-se a escolha em razão da Europa Ocidental ter sido o berço da Revolução Industrial e com ela, do surgimento do Desenho Industrial, termo que na língua portuguesa foi empregado para distinguir uma forma de trabalho específica e que hoje chamamos de Design (CARA, 2010: passim). Assim, o termo Desenho Industrial pode e deve ser compreendido como uma espécie de nomenclatura precursora para definir uma prática profissional, realizada por artistas e artesãos das primeiras fábricas européias, e que se iniciou com a Revolução Industrial. Desde esse período, a prática do Design é explicada como sendo uma atividade empregada para o dito aperfeiçoamento da mercadoria produzida em larga escala. Esse aperfeiçoamento, mais acima descrito como um "valor agregado" a um objeto industrial graças a uma virtude que seria própria aos profissionais de marketing e de design, não se limitava apenas à funcionalidade do objeto fabricado, mas também aos aspectos simbólicos que ele poderia trazer. Antes da Revolução Industrial, um objeto manufaturado era possuído por conta do seu valor de uso, consequentemente um casaco de inverno tinha valor se protegia o usuário do frio. $O$ outro tipo de valor, o valor simbólico poderia ser que esse casaco havia pertencido a um herói da Revolução Francesa, por exemplo. Esse outro valor é afetivo ou de natureza subjetiva, mas pode ser coletivo, tal como se verifica nos objetos de adoração religiosa, ou em uma bengala ou em um livro que tenha pertencido a alguém afetivamente importante para uma família ou para um grupo social.

O referido valor simbólico sempre diz respeito a coisas vividas e também sempre existiu em relação aos objetos. Porém, o presente estudo trata sobre o valor mercantil, um arbitrário cultural, que não deve ser confundido com um valor social ou útil para a sociedade, dependendo daquilo que o grupo social elege como possuindo valor, mas que também é um valor simbólico e que passará a ser aplicado para todos os objetos produzidos, seja pela indústria, seja pela produção artesanal. Majoritariamente nossa sociedade se interessa preferencialmente pelos valores preconizados pela ideologia comercial, daí a indiferença e o descarte dos objetos quando eles são baratos ou quando saem de moda. A dimensão simbólica dos objetos que antes se calcava em seu efetivo valor de uso, agora se apóia em seu valor de troca financeira, que também é simbólica, mas completamente descolada ou alienada das vivências sociais que lhe dão sustentação.

A corrente teórica majoritária do Campo do Design defende que o Desenho Industrial teria nascido, se não no final do século XVIII, conjuntamente com a indústria pesada, no decorrer do século XIX com a indústria de produção em massa, vindo a ser chamado de Design a partir do século XX, após a criação em Weimar da Bauhaus, em 1919. Segundo Adrian Forty (FORTY, 2007: 59), desde a década de 1750, momento da primeira Revolução Industrial, a indústria de cerâmica inglesa denominada Wedgwood já empregava modeladores cuja tarefa era a mesma que a dos famosos designers americanos da década de 1920, tais como Raymond Loewy ou Henry Dreyfuss, porém exercida de maneira mais humilde. Ou ainda: Na década de 1750, a modelagem não somente foi reconhecida como uma atividade separada, como também havia indivíduos descritos como modeladores cuja única tarefa era fazer protótipos para servir de base aos outros artífices 
(Ibid.:, id.: 50). Enfim, desde o início da Revolução Industrial pode-se afirmar que existe uma categoria profissional que se ocupa da funcionalidade do objeto industrial e também de sua configuração formal, acreditando que a configuração, uma dimensão simbólica, era tão demandada como a dimensão funcional ou utilitária. Nesse sentido, a dimensão do valor de uso e do valor de troca simbólica ficam embaralhadas, aliás, a prática profissional do designer era exatamente essa, valorizar tanto a dimensão funcional quanto a dimensão simbólica, transformando o objeto industrial em algo irresistível ao consumidor. Assim o projeto de design envolvia não apenas a confecção do objeto industrial, o seu valor de uso social ou utilitário, mas também a produção do desejo de que possuí-lo significava distinção e honradez.

Finalmente, explica-se o emprego acima do termo "aperfeiçoamento" para abranger não apenas as melhorias de natureza utilitária feitas para "atender" ao público consumidor e assim aumentar o volume de vendas e consequentemente o lucro gerado ao empresário, mas também o aspecto financeiro da produção, a fim de reduzir seus custos e mais uma vez potencializar a margem de lucros do industrial.

A necessidade histórica da prática do Desenho Industrial expressa por Forty (Ibid.:, id.: passim) serve, como se pensa no presente trabalho, para justificar a relevância do Design para a sociedade de consumo implementada progressiva e mundialmente a partir de meados do século $X X$, que apregoa, por exemplo, que a felicidade é ínsita ao consumo. $O$ ato de possuir ou consumir bens materiais ou serviços seria o caminho mais rápido, fácil, quiçá único, do ser humano encontrar a almejada felicidade. E o Design, com a estratégia de diferenciar, a espaços de tempo cada vez mais curtos, os bens industriais e serviços em minúcias que não alteram estruturalmente sua funcionalidade, participa na propagação da ideia do consumismo desenfreado, imaginado como desencadeador de felicidade. Leia-se:

Se a felicidade está permanentemente ao alcance, e se alcançá-la leva apenas os poucos minutos necessários para folhear as Páginas Amarelas e sacar o cartão de crédito, então, obviamente, um eu que não consiga atingir a felicidade não pode ser real ou genuíno, mas antes uma relíquia da indolência, ignorância ou inépcia. (BAUMAN, 2008: 27)

A pesquisa que se desenvolve em sede de doutorado abordará, em sequência, a produção agora já chamada artística da Época Moderna que se estende do Renascimento ao século XIX. Pretende-se estudar como o ensino do trabalho manual e artístico deixou de ser uma tarefa passada de pai para filho, ou de Mestre para aprendizes, seja no âmbito religioso ou secular, como o era na Idade Média, porém já em decadência a partir do século XII, em razão do intenso processo de urbanização vivenciado pela Europa Ocidental. Na Idade Moderna, além dos ateliês, surgiram as Academias, responsáveis pelo ensino das diversas práticas artesanais àqueles que podiam arcar com os custos de tal educação. Nessas instituições será, ainda, conferida importância ao novo status social diferenciado do artista, mais tarde estendida a determinados designers tidos como artistas. Como consequência desta distinção social, nasceu a diferenciação que se faz até os dias atuais entre a obra de arte e o trabalho artesanal, que passou a informar também o objeto 
industrial ou o objeto de Design. Finalmente, a pesquisa prosseguirá no estudo da arte contemporânea ocidental novamente no intuito de se construir pontes de comparação entre a Arte e o Design a partir do século XX. Será considerado o fenômeno apontado por Sennett, dentre outros pensadores, da redução atual do tempo dedicado ao desenvolvimento da capacitação profissional em comparação ao passado. Na tese em andamento serão consideradas as categorias profissionais dos artesãos, artistas e designers, a fim de se avaliar possíveis reflexos atuais desse treinamento encurtado em suas atividades de forte apelo visual. Sennett reflete sobre como poderão ser desenvolvidos talentos pessoais em uma época de mudanças rápidas das exigências da realidade, alertando para a negligência ou mesmo renúncia, em alguns casos, dos ideais de excelência e de direcionamento do artesanato:

\begin{abstract}
O segundo desafio diz respeito ao talento: como desenvolver novas capacitações, como descobrir capacidades potenciais, à medida que vão mudando as exigências da realidade. Em termos práticos, na economia moderna, a vida útil de muitas capacitações é curta; na tecnologia e nas ciências, assim como em formas mais avançadas de manufatura, os trabalhadores precisam atualmente se reciclar a cada período de oito ou doze anos. $O$ talento também é uma questão de cultura. A ordem social que vem surgindo milita contra o ideal do artesanato, de aprender a fazer bem apenas uma coisa, compromisso que freqüentemente pode revelar-se economicamente destrutivo. No lugar do artesanato, a cultura moderna propõe um conceito de meritocracia que antes abre espaço para as habilidades potenciais do que para as realizações passadas. (Sennett, 2006: 13-14)
\end{abstract}

O tópico acima abordado por Sennett no que diz respeito à manufatura dos objetos de modo geral, não é novo dentro do cenário das artes visuais. Henry Matisse (1869-1954), em correspondência enviada a Henry Clifford e escrita em 14 de fevereiro de 1948 (FLAM, 1995: 182183), já revelava sua preocupação quanto à formação dos jovens artistas de seu tempo e exprimia a necessidade de longo treinamento para a capacitação de um colorista experiente. Abaixo se transcreve trecho dessa carta em que o pintor indicou o mesmo problema que perdura na atualidade e que se acredita merecedor de reflexão atenta e cuidadosa por parte da sociedade contemporânea, em razão da busca por qualidade que normalmente orientou a atividade humana, não apenas no Campo da Arte.

\title{
Prezado Sr. Clifford:
}

Sempre tentei esconder meus próprios esforços e desejei que meus trabalhos tivessem a leveza e alegria de uma primavera que nunca deixa ninguém suspeitar dos trabalhos que custou. Então, tenho medo de que o jovem, vendo em meu trabalho apenas a facilidade aparente e a negligência no desenho, usará isso como uma desculpa para dispensar certos esforços que eu acredito necessários.

As poucas exposições que tive oportunidade de ver durante estes últimos anos me fazem temer que os jovens pintores estão evitando a lenta e dolorosa preparação que é necessária para a educação de qualquer pintor contemporâneo que afirme construir apenas com a cor ${ }^{4}$. Este trabalho lento e doloroso é indispensável. [...]

\footnotetext{
${ }^{4}$ Lembra-se que a querela entre os partidários da linha e os partidários da cor é antiga na França e remonta ao século XVII, tendo sido extensamente debatida entre poussinistes e rubenistes. As ideias conflitantes a respeito da supremacia da linha
} 
É só depois de anos de preparação que o jovem artista deve tocar em cor - não cor como descrição, [...], mas como um meio de expressão íntima. [...]

[...] Gostaria que as pessoas soubessem que não podem abordar a cor como se estivessem entrando na porta do celeiro ("entrer au moulin"); é preciso passar por uma preparação severa para se ser digno disso. [...] (Tradução nossa)

Um último capítulo a ser escrito terá o objetivo de estudar detalhadamente o Design como prática social. Com base nos achados e conclusões as quais se possa chegar, entender-se-á no que tal prática difere ou se assemelha à prática da Arte.

A presente pesquisa é basicamente teórica e por esse motivo optou-se pela metodologia bibliográfica, abrangendo publicações nacionais e internacionais do Campo do Design e das Artes Plásticas, e interdisciplinares nas áreas da História da Arte e da Sociologia. A obra escrita em volumes por Arnold Hauser, The Social History of Art, traduzida para o Português como História Social da Literatura e da Arte, servirá como moldura teórica para o estudo da arte e do artesanato. A bibliografia sobre o tema levantada cuidadosamente por Julius Von Schlosser, La Litterature Artistique (A Literatura Artística) ajudará para a identificação de obras relevantes, assim como os livros A pintura, texto essenciais cuja direção geral é de Jacqueline Lichtenstein e $A$ Documentary History of Art de Elizabeth Gilmore Holt, que reúnem textos escritos no passado por diversos artistas europeus desde a Idade Média até o século XX. Autores como Baxandall, Wollf, Pevsner, Rugiu e Sennett enriquecerão a lista de livros consultados. No tocante à conceituação da prática do design, os escritos de Gert Selle, Stéphane Vial, Bernd Löbach e Adrian Forty servirão de norte. Outras fontes bibliográficas serão identificadas no decorrer do projeto.

\section{CONCLUSÃO}

A pesquisa de doutorado que se desenvolve apresenta-se ainda em estágio inicial. O problema verificado reside no fato da fronteira entre a atividade profissional das artes visuais e do design configurar-se ainda fluída, nebulosa, em razão do passado comum que compartilham, ou seja, o artesanato. Tal fato clama por um estudo aprofundado de suas semelhanças e diferenças, a fim de se pensar um estatuto ontológico do Design, baseado em um amplo diálogo entre os setores interessados. Humildemente se acredita que esse seria um caminho frutífero a ser trilhado para a afirmação, ou não, do Design como um Campo distinto do saber, como uma ciência. O primeiro capítulo já elaborado da tese elegeu por recorte o período medieval da Europa Ocidental pelos seguintes motivos: na Europa Ocidental se deu a Revolução Industrial que fará nascer, a partir do século XVIII, a necessidade da atividade do desenhista industrial, profissional este posteriormente denominado designer; faz-se mister estudar o período medieval pois nesse longo interregno de tempo se encontram as raízes das mudanças de uma sociedade de economia natural para uma de base monetária e, mais tarde, capitalista. Outra razão para o recorte é o fato do período em questão ter sido palco de mudanças na prática do artesanato, relativas à sua manufatura e ensino, cujos reflexos se fazem ouvir ainda na atualidade e que foram a semente da distinção criada no Renascimento entre as figuras do

versus a supremacia da cor, defendidas por partidários de Poussin e de Rubens ao final do século XVII, geraram acalorado debate que se estendeu por séculos, tendo os pintores Ingres e Delacroix como artistas representativos das duas correntes opostas no século XIX. 
artesão e do artista. Sendo certo que, nos dias atuais, uma aura de artista é emprestada a determinados designers, percebe-se aqui um dos pontos de semelhança entre esses dois agentes, o que justifica um estudo mais aprofundado a ser realizado no desenrolar dos capítulos da tese de doutorado em andamento.

\section{Bibliografia}

BAXANDALL, Michel. Painting and Experience in Fifteenth Century Italy. Oxford: Oxford University Press, 1988

BAUMAN, Zygmunt. A arte da vida. Rio de Janeiro: Zahar, 2009.

BOURDIEU, Pierre. A economia das trocas simbólicas. São Paulo: Perspectiva, 2007

CARA, Milene. Do Desenho Industrial ao Design no Brasil. São Paulo: Blücher, 2010.

DENIS, Rafael Cardoso Denis. Design para um Mundo Complexo. São Paulo: Cosac Naify, 2012, disponível em Google books, acesso em 05/03/2018.

FLAM, Jack D., Matisse on art. Berkeley, Los Angeles, London: University of California Press, 1995.

FORTY, Adrian. Objetos de desejo, design e sociedade desde 1750. São Paulo: Cosac Naify, 2007.

HAUSER, Arnold. História Social da Literatura e da Arte. Tomo I. São Paulo: Editora Mestre Jou, 1982.

HAUSER, Arnold. The Social History of Art. Vol. I: From Prehistorical Times to the Middle Ages. London and New York: Routledge, 1999.

HOLT, Elizabeth Gilmore. A Documentary History of Art, Vol. I: The Middle Ages and the Renaissance. New Jersey, Princeton USA: Princeton University Press, 1981.

LICHTENSTEIN, J. (org.) A pintura. Vol. I. O mito da pintura. São Paulo: Ed. 34, 2004, p. 73-86. Fonte da tradução: Fonte: Plínio, o Velho, História natural, edição do texto latino in Plinel'Ancien, Histoire naturelle .Paris: Les BellesLettres, 1985, I. XXXV, p. 63ss.

LÖBACH, Bernd. Design Industrial. Bases para a Configuração dos Produtos Industriais. São Paulo: Editora Edgar Blucher, Ltda., 2001.

NOCHLIN, Linda. Why Have There Been No Great Women Artists? In.: ARTNews, 1971, traduzido por Juliana Vacaro, Por que não houve grandes mulheres artistas?, São Paulo: Edições Aurora, 2016, disponível em www.edicoesaurora.com/ensaios/Ensaio6.pdf, acesso em 05/03/2018.

PARKER, Rozsika; POLLOCK, Griselda. Old Mistresses. Women, Art and Ideology. London, New York: I. B. Tauris \& Co Ltd, 2013 
PEVSNER, Nikolaus. Academias de arte: passado e presente. São Paulo: Companhia das letras, 2005.

RUGIU, Antonio Santoni. Nostalgia do mestre artesão. Campinas: Autores associados, 1998.

SCHLOSSER, Julius Von. La Littérature Artistique. Manuel des sources de l'Histoire de L'art Moderne. France: Flammarion, 1984

SELLE, Gert. Ideología y utopía del diseño: contribución a la teoría del diseño industrial. Barcelona: Editorial Gustavo Gili, S.A., 1975.

SENNETT, Richard. O Artífice. Rio de Janeiro: Editora Record, 2009.

SENNETT, Richard. A cultura do novo capitalismo. Editora Record, 2006.

VIAL, Stephane. Le paradoxe du design: Où l'on montre que le design pense, mais ne se pense pas. In.: S. Vial, Court traité du design. Paris: Presses Universitaires de France, 2010, pp. 11-14.

VIAL, Stéphane. Court traité du design. France: Puf, 2014.

WOLFF, Janet. A produção social da arte. Rio de Janeiro: Zahar Editores, 1982. 